\title{
Cloud versus On-Premise Computing
}

\author{
Cameron Fisher \\ Massachusetts Institute of Technology, Cambridge, USA \\ Email: cafisher@mit.edu
}

How to cite this paper: Fisher, C. (2018) Cloud versus On-Premise Computing. American Journal of Industrial and Business Management, 8, 1991-2006.

https://doi.org/10.4236/ajibm.2018.89133

Received: June 13, 2018

Accepted: September 27, 2018

Published: September 30, 2018

Copyright $\odot 2018$ by author and Scientific Research Publishing Inc. This work is licensed under the Creative Commons Attribution International License (CC BY 4.0).

http://creativecommons.org/licenses/by/4.0/

\begin{abstract}
When investigating new choices for enterprise solutions, decision-makers need to increasingly weigh the merits of Cloud offerings. Accessibility, performance and security are key requirements along with vendor reputation and user community. The race to acquire customers and expand market share is prompting vendors to offer attractive introductory pricing to capture Cloud tenants. To keep in mind long term TCO and business outcomes, it's essential to conduct due diligence to minimize risks or surprises. Knowing the business, technology and contractual drivers will inform the decisions on the future of Cloud at your organization. Decisions to embrace the Cloud will always require complete analysis of the options and business metrics. After performing a full needs analysis and understanding the variables, a reliable and cost-effective result is better selected and managed. This paper outlines fundamentals to understand the implications for deciding on Cloud versus On-Premise Computing going forward.
\end{abstract}

\section{Keywords}

Cloud, On-Premise, Computing, Contract Negotiation

\section{Introduction}

To evaluate the best solution application and platform at a medium-sized organization, the projected cost structure pointed to a sizeable multi-year investment in Cloud services. Enlisting computing services from outside the firewall defines Cloud computing as distinct from On-Premise computing.

In the example discussed below, cumulative Cloud subscription costs are estimated to exceed $\$ 2$ million over a 10 -year time frame. Prior to making such sizeable Cloud commitments, organizations of all sizes should be aware of the business factors and cost drivers involved. Before signing any contracts, it's necessary to understand the available choices and comparative cost structures. The 
following research is inspired by real word events. The data is illustrative and representative as a case study for learning purposes.

Research, analysis and formal RFP (Request for Proposal) efforts led to narrowing the field of potential suppliers. Two finalists were down-selected from 10 candidate suppliers. Next, the challenge was to evaluate the proposals of each supplier respectively to gain insights.

For example, is the Cloud better than an On-Premise approach? Why or why not? When, how, what and from which supplier? Is the Cloud more cost-effective? As examined below, it depends. A range of attributes determine the comparative Total Cost of Ownership (TCO). Therefore, examining the model to assess operations and decompose availability and flexibility proves helpful to deciding on Cloud versus On-Premise computing.

\section{Case Study and Research Findings}

At this point in the revolution for Cloud software as a service, vendors attractively price their proposals to stake out maximum market share. A heated quest to survive and thrive amid disruption, transition and market shakeout is underway that includes innovators, acquisition-targets and established large vendors.

This paper's scenario assumes competing vendors fielded questions and performed proof-of-concept exercises and "conference room" prototypes. As Top-to-Top negotiation meetings grew closer, the CIO remarked metaphorically: "Let's give both vendors a sharp knife, lock them in a bitter fight, and see who emerges with the best proposal."

For our illustrative example, the vendors' solutions promised to offer important features and system management strengths. Vendor 1 offered the solution in both a) Cloud and b) On-Premise. Vendor 2 offered only the Cloud subscription approach.

Through research as well as Trial and Error, the choices are narrowed down. This case study points out the lessons learned and pitfalls to avoid. "Kicking the tires" in this case, demonstrated three options were viable for $1 \mathrm{a}, 1 \mathrm{~b}$ and 2 enumerated above. And if that dictates an On-Premise proposal competes with the same firm's Cloud approach, that's fine, too. One vendor's legacy application had its origins in On-Premise, so care was taken to investigate their maturing go-to-market positioning, Cloud strategy and roadmap.

\section{The Basics of Cloud}

Taking services outside the firewall is a popular way to define "What is Cloud computing". The most prominent Cloud platforms come from Microsoft, Google and Amazon. Specific solutions leverage these platforms so that developers and content producers can offer users access to functionality. With subscription entitlements and permissions, organizations can configure and administer a multi-tenant compute capability. This occurs via the internet across distances, and over a firewall using a web browser. 
As illustrated in Figure 1, our daily lives increasingly interact with a centralized computing capability that scales as volumes increase for data traffic of many types and sources. The endpoints can include phones, tablets, PCs, laptops, wearables and Internet of Things (IoT). For example, sensors on machines at a manufacturing plant can transmit vibration metrics as an early detector prior to failure.

Proponents trumpet the merits of Cloud as:

- Flexible up-front investment costs

- Frequent and easier product upgrades

- Reduced IT support performed by internal resources

- Community of users for the latest versions and features

- Efficient for multi-tenant usage (scalability, recoverability, patching, security) With elastic compute capabilities, the legacy challenge of over-provisioning or under-utilization of On-Premise assets can be reduced. However, Cloud related fees can arise for transaction count, storage usage, instance quantity, API or single sign-on that are less obvious. These attributes must be considered when selecting and managing Cloud solutions.

\section{Business Objectives}

Key differentiators boiled down to which solution better fit the business requirements for:

- Domain functionality

- Performance, availability and security reliability

- Ease-of-navigation (users and system administrators)

- Implementation services

- Training \& post-deployment customer care

- References and reputation

- Organization depth and stability

- Total long-term cost of ownership

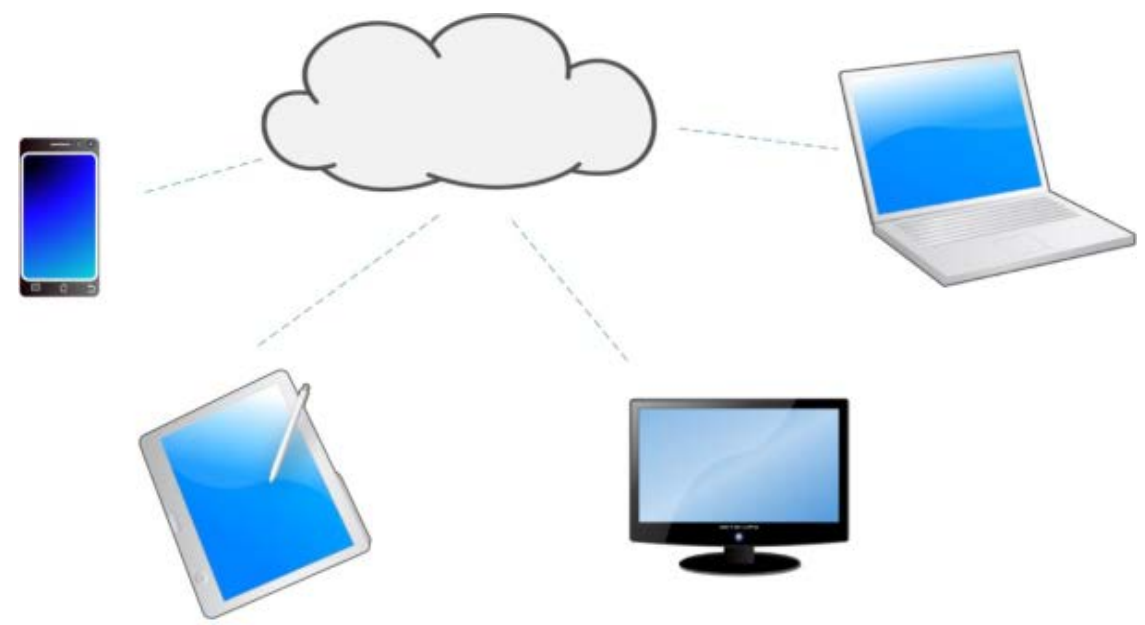

Figure 1. Illustration-The basics of Cloud. 
With three options to go forward-the goal was to identify the best path forward, since all three choices had satisfied minimum requirements. For the last bullet on the above list, a drill-down into factors that affect long term costs and success was deemed worthwhile.

The Cloud enables a new approach to deploy and use vital enterprise applications. However, the seemingly straightforward framework creates a myriad of new complexity [1].

\section{The Allure of Cloud}

Vendors trumpet the Cloud model citing merits such as accessibility, flexibility and efficiency. However, gaining deeper insight about the Cloud versus On-Premise frameworks reveal lessons that inform the decision-making.

On-Premise involves cost components that require self-reliance for factors such as: On-site server setup, server software, System administration FTE labor and other infrastructure costs when compared to a subscription to a centralized host (aka Cloud). Skipped maintenance fee payments can lead to missed updates on features and fixes.

The application provider may host its solution itself, or partner with a platform provider (e.g. Amazon Web Services, Microsoft Azure, Google App Engine, etc.). Essentially, Cloud subscriptions do not come with software ownership licenses, only the right to use a service from the centrally hosted solution for the duration of the agreement period. A perpetual license is owned, and can go unused for periods of time, lapse on annual maintenance payments and then later used.

In contrast, a subscription is uninterruptible. Vendors effectively promote the merits of computing in the Cloud. The majority of new application contracts for HR, ERP and CRM applications choose Cloud. To advance their own interests, application vendors are constraining or sun setting their On-Premise product offerings. Vendors prefer the predictability and continuity of revenue and customer stickiness that Cloud delivery enables.

Application vendors exert a preference for the Cloud. Some sales executives might explain the two cost structures for Cloud versus On-Premise as being "about 4 years to break-even" among the two choices. Of course, results can vary for a specific situation and arrangement, but this example demonstrates that a purported 4-year intersection overstates the attractiveness of Cloud.

\section{Pricing and Terms}

Both vendors seemed aware of their competitors because the proposals had similar pricing and terms. Each proposal was attractive as compared to official List prices at the start of negotiations. The vendors expressed strong interest in adding to their portfolio of clients in our industry's sector, and to extend/embrace suitable new features we may suggest for future releases. In this manner, future improvements could become accessible to their entire customer base and in- 
crease the vendor's appeal and revenues.

It became apparent that in their race for Cloud market share, the supplier hoped to secure early loyalty for the long term, even if the supplier bore a loss-leader for introductory years [2].

Deciphering true net pricing (after discounts were taken off List prices) and any variable vendor fees for transactions, storage, API's, single sign-on, etc. also warranted caution to navigate caveats, conditions and potential pitfalls. Scrutinizing computing performance metrics, SLAs, support coverage and commercial contract terms occurred. At this point, the immediate task was to assess "The TCO” for a 10-year horizon, not simply the attractive initial years.

\section{Calculating Cost Metrics and Comparisons}

Assume the following cost structure for illustration purposes:

$C 1=$ Count of Full features annual license type requirements

$C 2=$ Count of Basic features annual license type requirements

P/12 = Annual Fee of a Cloud subscription per named user per month

$P 1=$ Annual Fee of a Cloud subscription per named user (License Type:

“Full")

$P 2=$ Annual Fee of a Cloud subscription per named user (License Type: "Basic")

$2 P 1=$ Full features On-Premise Perpetual License to purchase

$2 P 2=$ Basic features On-Premise Perpetual License to purchase

Now, simplify the scenario to first focus only on Full feature licenses

User Count: 1000

User Type Mix: 1000 Full; 0 Basic

Annual Software Maintenance Fee if On-Premise: 18\%

Let $\mathrm{P}=\$ 3000$

If 1000 Full users immediately and 0 Basic users, then solve for $\mathrm{T}$

$(\mathrm{C} \times 0.5 \mathrm{P} \times \mathrm{T})=(\mathrm{C} \times \mathrm{P})+(\mathrm{C} \times 0.18 \mathrm{P} \times \mathrm{T})$

$1000 \times \$ 3000 \times \mathrm{T}=1000 \times \$ 6000+1000 \times \$ 1080 \times \mathrm{T}$

$\$ 3,000,000 \times \mathrm{T}=\$ 6,000,000+\$ 1,080,000 \times \mathrm{T}$

$\mathrm{T}=\$ 7.08 / 3$

$\mathrm{T}=2.36$ Years

However, if the count, mix or pricing ratio of On-Premise versus Cloud was different, the timing of the "cross-over" could vary as in Table 1.

Table 1. On-Premise versus Cloud Ratio.

\begin{tabular}{ccc}
\hline On-Premise/Cloud & Annual Maintenance $=0.18$ & Annual Maintenance $=0.20$ \\
\hline 2.00 & 2.36 years & 2.40 years \\
1.75 & 2.07 years & 2.10 years \\
1.50 & 1.77 years & 1.80 years \\
1.30 & 1.48 years & 1.50 years \\
\hline
\end{tabular}


Table 1 points out that the higher the $\mathrm{O} / \mathrm{C}$ ratio, the longer is $\mathrm{T}$ before owning is a less costly proposition than subscribing or "renting" off-premise computation capabilities. Similarly, the higher is Annual Maintenance percentage, the longer is $\mathrm{T}$ before owning is less costly than Cloud, aka Software as a Subscription.

Introducing a varying mix of license types would affect the weighted average price among license types, but assuming the $\mathrm{O} / \mathrm{C}$ ratio and the Annual Maintenance percentage remain consistent, the relationships stay the same. Keep in mind, that ownership usually involve more hands-on efforts on-site, compared to Cloud. Upgrades, patches, hardware administration, etc. add to annual internal IT staffing costs. Higher counts of users will generally enable more economies of scale are realized from On-Premise.

Typically, vendors use discrete 12-month anniversary dates to determine entitlements and contract renewal dates. The quantity of years in a license or maintenance contract period could be 1 or more. Discrete years rather than pro-rated periods are common to the Master Services Agreement. Therefore, defining the duration options and price freeze periods for future license or maintenance agreements is a key factor when negotiating mutual commitments and contracts.

After 10 years, the TCO for Cloud shows \$30,000 whereas On-Premise totals $\$ 16,800$. For our example in Table 2, On-Premise tallied about $56 \%$ as expensive as 10 years of Cloud expenses.

Purchase and installation costs can be capitalized for tax advantages. In contrast, Cloud subscription can be accounted as an operating expense. Smaller organizations that are short on working capital may be attracted to Cloud due to lower cost requirements during early years. With fewer users, impact of On-Premise infrastructure support may also be relatively more burdensome. Figure 2 below illustrates that by Year 3, it will typically trend less costly for an On-Premise approach, even if 1 or 2 extra FTE is deemed necessary to support On-Premise.

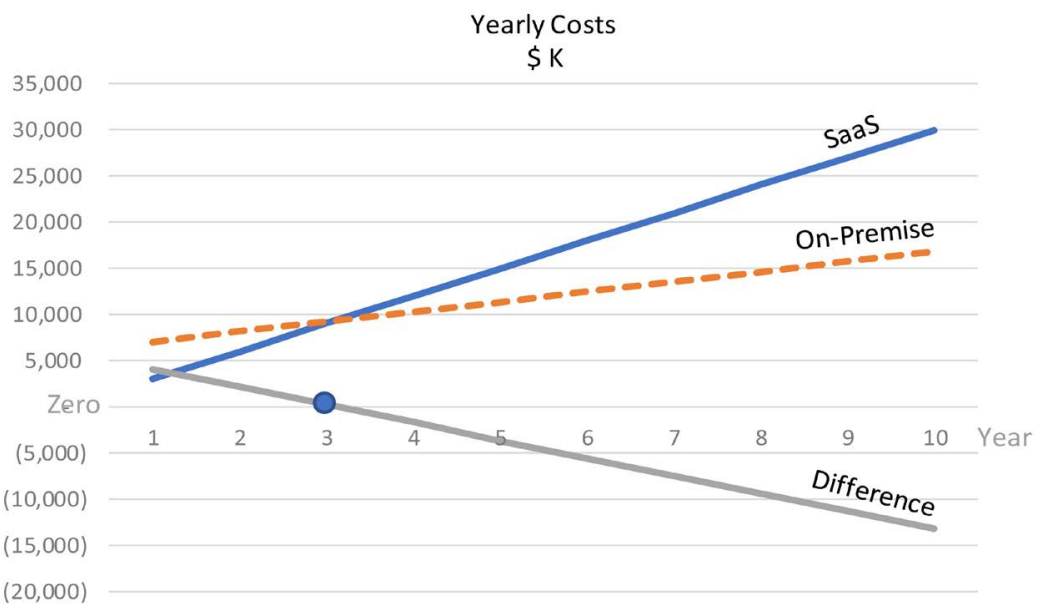

Figure 2. Yearly costs of Cloud subscription versus On-Premise. 
Table 2. Yearly cost difference of Cloud versus On-Premise.

\begin{tabular}{|c|c|c|c|c|c|}
\hline \multirow{2}{*}{ Yr } & \multirow{2}{*}{$\begin{array}{c}\text { Cloud } \\
\text { Subscription }\end{array}$} & \multicolumn{2}{|c|}{ On-Premise } & \multirow{2}{*}{$\begin{array}{l}\text { Ann } \\
\text { Diff }\end{array}$} & \multirow{2}{*}{$\begin{array}{c}\text { Cum } \\
B /(W)\end{array}$} \\
\hline & & Purchase & Maint'ce & & \\
\hline Initial & & 6000 & & 6000 & 6000 \\
\hline 1 & 3000 & & 1080 & (1920) & 4080 \\
\hline 2 & 3000 & & 1080 & (1920) & 2160 \\
\hline 3 & 3000 & & 1080 & (1920) & 240 \\
\hline 4 & 3000 & & 1080 & (1920) & $(1680)$ \\
\hline 5 & 3000 & & 1080 & (1920) & $(3600)$ \\
\hline 6 & 3000 & & 1080 & (1920) & $(5520)$ \\
\hline 7 & 3000 & & 1080 & (1920) & (7440) \\
\hline 8 & 3000 & & 1080 & (1920) & $(9360)$ \\
\hline 9 & 3000 & & 1080 & (1920) & $(11,280)$ \\
\hline 10 & 3000 & & 1080 & (1920) & $(13,200)$ \\
\hline Total & 30,000 & 6000 & 10,800 & & \\
\hline
\end{tabular}

In the example illustrated by Figure 2, the cross over occurs by Year 3. Prior to Year 3, Cloud subscription incurs less out-of-pocket costs than On-Premise.

\section{Additional Complexity: Gradual Ramp-Up and Multiple License Types}

When user counts are not immediately at full population, counts are ramped up gradually as adoption increases beyond the initial years. Since the weighted mix of Full and Basic affects the calculation, we can use the specific values of our example scenario to solve for what is quantity of years $(\mathrm{T})$ :

More specifically,

License Purchase (Non-Recurring)

Year 1: $300 \times \$ 6000+700 \times \$ 500 \times 0.10=\$ 215,000$
Year 2: $300 \times \$ 6000+700 \times \$ 500 \times 0.20=\$ 430,000$
Year 3: $300 \times \$ 6000+700 \times \$ 500 \times 0.40=\$ 860,000$
Year 4: $300 \times \$ 6000+700 \times \$ 500 \times 0.25=\$ 537,500$
Year 5: $300 \times \$ 6000+700 \times \$ 500 \times 0.05=\$ 107,500$
Tatal: $\$ 2,150,000$
License Maintenance (Recurring)

Year 1: $0.18 \times \$ 215,000=\$ 38,700$

Year 2: $0.18 \times(\$ 215,000+\$ 430,000)=\$ 116,100$

Year 3: $0.18 \times(\$ 215,000+\$ 430,000+\$ 860,000)=\$ 270,900$

Year 4: $0.18 \times(\$ 215,000+\$ 430,000+\$ 860,000+\$ 537,500)=\$ 367,650$

Year 5: $0.18 \times(\$ 215,000+\$ 430,000+\$ 860,000+\$ 537,500+\$ 107,500)=$ $\$ 387,650$

Total: $\$ 1,181,000$ 


\section{Cloud (Recurring)}

Year 1: $300 \times \$ 3,000+700 \times \$ 250 \times 0.10=\$ 107,500$

Year 2: $300 \times \$ 3,000+700 \times \$ 250 \times 0.30=\$ 322,500$

Year 3: $300 \times \$ 3,000+700 \times \$ 250 \times 0.70=\$ 752,500$

Year 4: $300 \times \$ 3,000+700 \times \$ 250 \times 0.95=\$ 1,021,250$

Year 5: $300 \times \$ 3,000+700 \times \$ 250 \times 1=\$ 1,075,000$

1 Years Cloud $=\$ 107,500$

1 Year On-Premise $=\$ 215,000+\$ 38,700=\$ 253,700$

Cloud/On-Premise $=42.4 \%$

Cum. 2 Years Cloud $=\$ 107,500+\$ 322,500=\$ 430,000$

Cum. 2 Years On-Premise $=\$ 645,000+(\$ 38,700+\$ 116,100)=\$ 799,800$

Cloud $/$ On-Premise $=53.8 \%$

Cum. 3 Years Cloud $=\$ 107,500+215,000+\$ 752,500=\$ 1,075,000$

Cum. 3 Years On-Premise $=(\$ 645,000+\$ 860,000)+\$ 270,900=\$ 1,775,900$

Cloud $/$ On-Premise $=60.1 \%$

4 Years Cloud $=\$ 107,500+215,000+\$ 752,500+\$ 1,021,250=\$ 2,096,250$

4 Years On-Premise $=(\$ 1,505,000+\$ 537,500)+\$ 367,650=\$ 2,410,150$

Cloud/On-Premise $=87.0 \%$

5 Years Cloud $=\$ 107,500+215,000+\$ 752,500+\$ 1,021,250+\$ 1,075,000=$ $\$ 3,171,250$

5 Years On-Premise $=(\$ 2,150,000)+\$ 387,650=\$ 2,537,650$

Cloud/On-Premise $=125.0 \%$

Due in part to the pace in adoption rates and the discrete one-year periods of maintenance obligations tied to perpetual license purchases.

A key consideration is to not pay for licenses prior to users are ready to adopt and derive value. Commit to paying for what's needed and used. Do not commit to an expanded footprint of extra's. Vendors may attempt to offer an attractive price for a full initial population, the situation organizations face will vary. Some projects will intentionally ramp-up more slowly than others due to implementation partners' consultative approach (e.g. piloting), organizational change management readiness, resource availability, etc. [3].

In our example of S-curve adoption ramp-up for user population adoption of the project, the data graph is showing a cross-over at Year 3.

In the above example scenario, a premium of " $2 \mathrm{x}$ " Cloud pricing, grants to a license purchaser the perpetual right for named users of a software solution. For this example, an $18 \%$ annual maintenance fee applicable to perpetual On-Premise licenses applies. Vendors charge annual fees for software maintenance and support fees. As a percentage of license purchase price, the fees are typically $18 \%, 20 \%$ or $22 \%$.

Now, let's depict a typical "S" growth curve for on-boarding users as training, organizational change and adoption activity occur within the client organization for a future set of users forecasted to total 1000 as shown below. Figure 3 illustrates a "S" curve which is initially modest growth, then intensified, then plateauing. 


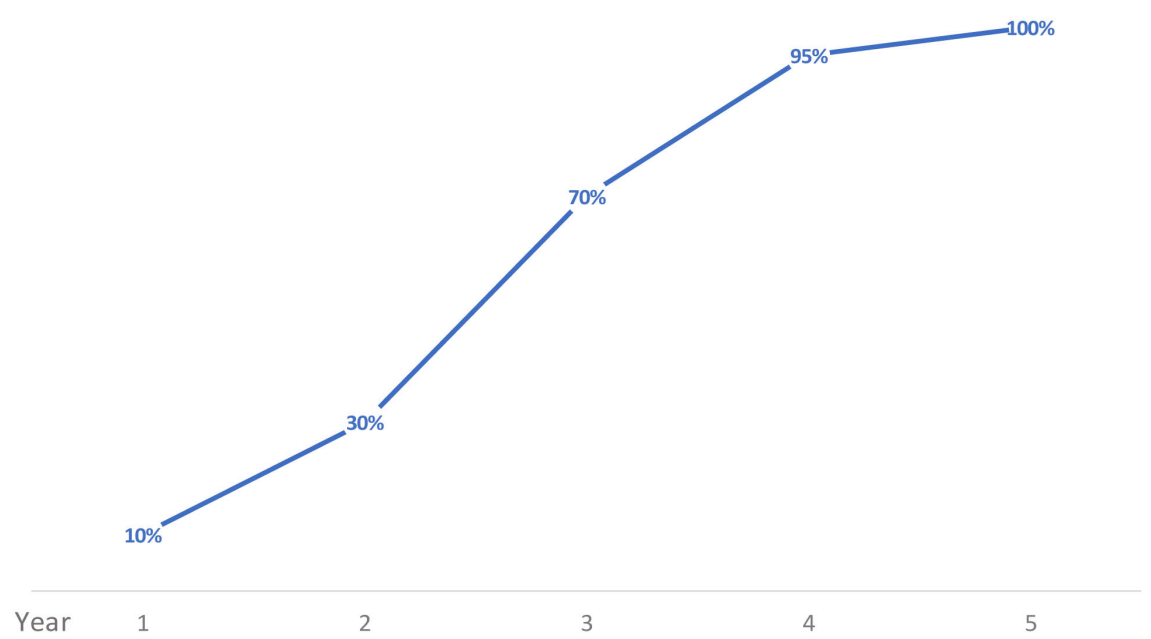

Figure 3. Illustration of simplified S-curve growth adoption. Year $1=10 \%$; Year $2=30 \%$; Year $3=70 \%$; Year $4=95 \%$; Year $5=100 \%$.

Since the ramp-up for users to embrace and become productive with the new solution will take a few years, the below graph illustrates the user growth and related cost ramp-up for either a Cloud subscription or purchases of perpetual licenses.

Although a vendor may attempt to exert pressure for quick signatures on contracts, it's important to resist commencing payments on a solution until the organization (management as well as users) are sufficiently poised and trained to derive business benefits.

The table below illustrates the economics for a hypothetical example. Table 3 compares a 5-year structure that could be encountered versus a comparatively less expensive On-Premise cost structure.

Figure 4 below graphically illustrates the comparative annual run rates of Cloud subscription costs versus On-Premise licensing costs. During the later years of Year 4 thru Year 10, On-Premise license maintenance costs run at a considerably lower rate per year than Cloud subscription costs (Table 4).

As expected, Cloud can be less costly during initial years due to lower upfront capitalize-able expenditures. However, for a longer-term horizon, On-Premise can prove less costly. A key factor when comparing different approaches is to accurately estimate the internal costs that self-reliance would incur for On-Premise.

Table 2 shows after year 4, less per year is spent for On-Prem. On a cumulative basis, due to ramp-up which pushes cross-over point later, after Year 6 is when On-Premise is cumulatively less costly. Thereafter, the run rate for On-Premise maintenance fees are substantially less costly than the run rate for annual Cloud subscription costs at full user population levels. Beware that vendors may attempt upsell prior to contract expiration to nullify earlier established price protection. For example, add-ons or "Next Generation" enhancements could be treated as new products that circumvent renewal protection and are often ineligible for price hike caps. 
Table 3. 5-year cost structure comparison example. Comparison: (a) Cloud subscription: $\$ 3000$ and $\$ 250$ annually; (b) On-Premise: $\$ 6000$ and $\$ 500$ to purchase + annual maintenance.

(a)

\begin{tabular}{ccccccc}
\hline & $\mathbf{1}$ & $\mathbf{2}$ & $\mathbf{3}$ & $\mathbf{4}$ & $\mathbf{5}$ & Total \\
\hline Full Subscription @ $\$ 250 / \mathrm{u} / \mathrm{m}$ & 90 & 270 & 630 & 855 & 900 & 2745 \\
Basic Subscription @ $\$ 21 / \mathrm{u} / \mathrm{m}$ & 18 & 53 & 123 & 166 & 175 & 534 \\
Deployment Consulting & 100 & & & & & \\
$\quad$ Annual Maintenance & & & & & & \\
$\quad \begin{array}{c}\text { Self-Reliant IT Costs } \\
\text { Total Cloud }\end{array}$ & 208 & 323 & 753 & 1021 & 1075 & 3279 \\
\hline
\end{tabular}

(b)

\begin{tabular}{|c|c|c|c|c|c|c|c|}
\hline & Start & 1 & 2 & 3 & 4 & 5 & Total \\
\hline Full License Purchase @ $\$ 6000$ & 180 & 360 & 720 & 450 & 90 & $0^{1}$ & 1800 \\
\hline Basic License Purchase@ $\$ 500$ & 35 & 70 & 140 & 88 & 18 & 0 & 350 \\
\hline Deployment Consulting ${ }^{2}$ & & 100 & 2 & & & & 100 \\
\hline Annual Maintenance & & 39 & 116 & 271 & 368 & 388 & 1180 \\
\hline Self-Reliant IT Costs ${ }^{3}$ & & 100 & 100 & 120 & 100 & 100 & 520 \\
\hline Total On-Premise & 215 & 669 & 1076 & 929 & 576 & 488 & 3952 \\
\hline
\end{tabular}

Notice that five years into this project, On-Premise shows a run rate at approximately $50 \%$ less costly than Cloud. In other words, for the conditions set forth in this example's pricing and cost structures, the organization's annual maintenance costs on the licenses purchased, plus internal self-reliance costs added together, will run considerably less than the Cloud subscription rates during years $6-10 .{ }^{1}$ Assumes new users added plateaus at years $6-10{ }^{2}$ Assumes On-Premise and Cloud require equal deployment consulting, although Cloud may enjoy efficiencies from repeatable design, integration or other tasks. ${ }^{3}$ Assumes simplified cost elements pertain for in-house solution upgrade releases, system administration, periodic server hardware refresh, periodic server software refresh, networking, etc. ${ }^{4}$ Assumes no incremental storage or transaction fees for Cloud, which may vary by platform. ${ }^{5}$ Assumes license purchases occur in period N-1 with annual maintenance costs incurred in period N. ${ }^{6}$ Ignores tax effects of capitalizing software, hardware, labor, etc.

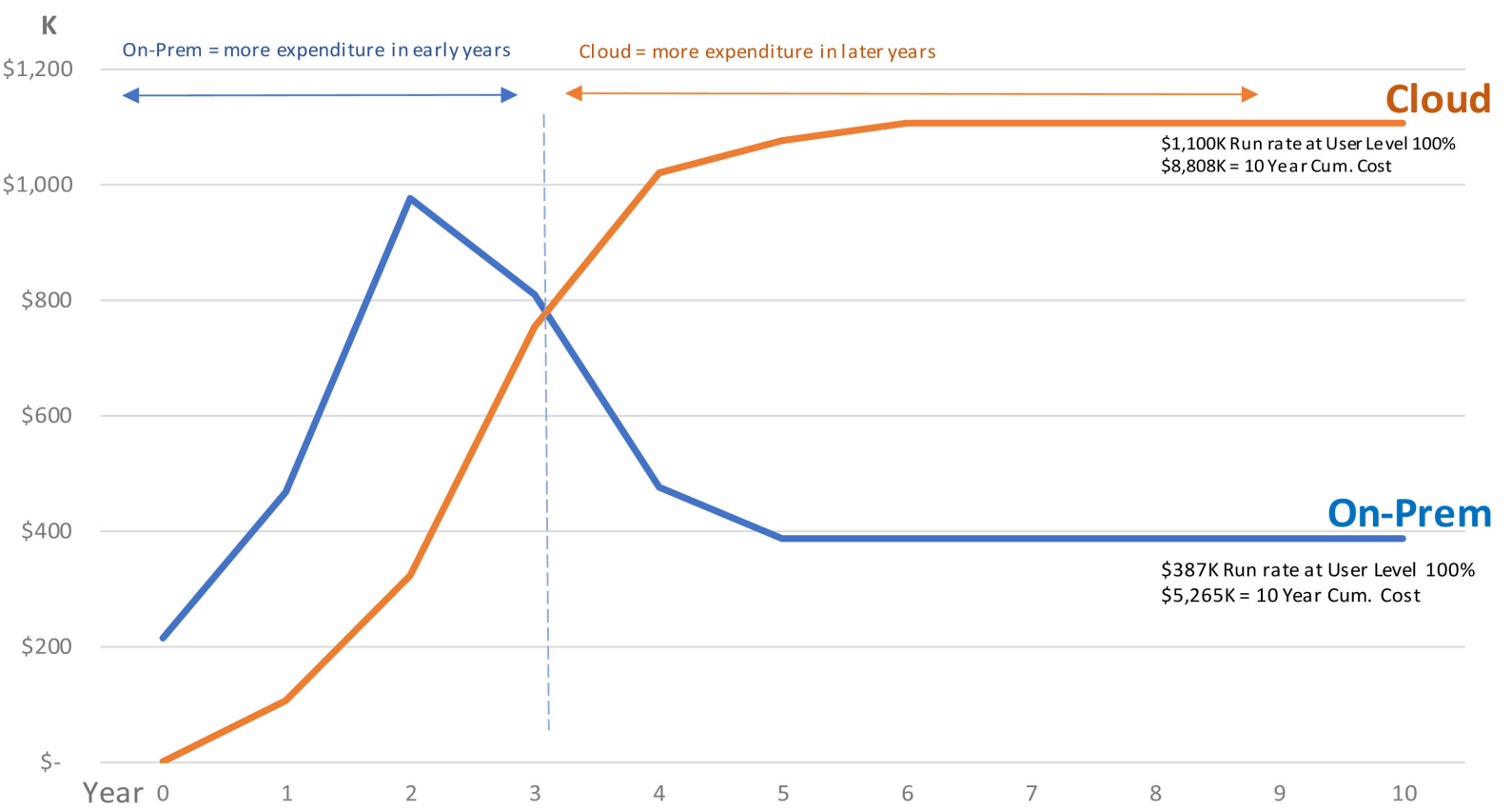

Figure 4. Cloud versus On-Premise-10 year comparison of costs. 
Table 4. Timeline of cross-over and cumulative break-even for Cloud versus On-Prem.

\begin{tabular}{|c|c|c|c|c|c|c|c|c|c|c|c|c|c|}
\hline & & & 1 & 2 & 3 & 4 & 5 & 6 & 7 & 8 & 9 & 10 & \\
\hline Year & $\mathrm{B} /(\mathrm{W})$ & (215) & (361) & (594) & (46) & 410 & 470 & 360 & 327 & 298 & 271 & 246 & \\
\hline Cumulative & $B /(W)$ & (215) & (576) & (1170) & (1217) & (806) & (336) & 24 & 351 & 649 & 919 & 1165 & 2666 \\
\hline
\end{tabular}

After 5 years, this example's cumulative net present value of costs is similar between Cloud and On-Premise. However, by the end of 10 years, On-Premise has gained a substantial cost advantage.

\section{Advantages for On-Premise}

1) Lines intersect after approximately 3 years from start of this project timeline. Thereafter, On-Premise costs remain below Cloud cost levels.

2) This simplified example assumes no incremental Storage fees (e.g. On-Premise capabilities are used to link supplementary attachments to records). If vendor fees for hosting transactions or storage do pertain, the relative attractiveness of On-Premise will increase to the extent in-house costs with allocations are well managed and less costly than vendor rates.

3) Some smaller vendors have not yet refined their Cloud capabilities. A mature On-Premise solution that has a lengthy track record could encounter difficulty transitioning to Cloud offerings.

4) Frequency of useful functional upgrades and speed of vendor versus in-house pace would increase attractiveness for Cloud. Typically, Cloud is updated quarterly from a centralized provider. On-Premise license release improvements maybe less frequent, such as semi-annually. Depending on the industry, a less frequent update schedule may impact the business positively or negatively.

5) On-Premise is less vulnerable to price increase, data leakage or external security threats (assuming internal security is mature). For Cloud, after business processes are closely meshed and tied to a vendor, the vendor could strive to increase annual pricing, introduce new variable fees for transactions and/or storage or otherwise bundle items into a growing footprint.

6) More skills acquisition can occur among employees, which can be documented and become part of the skills and culture.

7) In this example, a purchase of a named Perpetual License is quoted at roughly $2 \mathrm{x}$ the annual subscription rental rate. If this On-Premise/Cloud ratio grows above 2, then Cloud will become increasingly attractive, and the two cost lines intersect sooner. If this On-Premise/Cloud ratio grows below 2, then On-Premise will is increasingly attractive, and the two cost lines intersect later in the timeline.

8) If projected savings identifiable are reliably attributable to introducing the new solution, deducting each year's projected costs from the stream of benefits can reveal estimates for IRR, Payback period, Net Present Value and other project metrics [4].

9) Tax benefits of capitalizing On-Premise license purchases are not detailed here. The tax effects of capitalizing versus expensing and other accounting factors can vary by each organization's marginal tax rates. Typically, the relative at- 
tractiveness of On-Premise would improve due to capex tax incentives or other federal and state investment tax credits.

\section{Advantages for Cloud}

1) While the lines intersect at year 3, On-Premise cumulative costs are higher than Cloud, even by end-of-Year 5. Later, during years 6 - 10 is where On-Premise is comparatively cost-effective versus Cloud, with a run rate of nearly $\$ 1000 \mathrm{~K}$ of Cloud subscription fees versus a run rate of $\$ 400 \mathrm{~K}$ for On Premise maintenance (non-discounted) plus estimated $\$ 100 \mathrm{~K}$ annually for self-reliance using internal IT support resources, compared to Cloud.

2) Cloud can also require some integration costs. However, given Vendors' ready access to specialized expertise and history of pre-built connectors, integration efforts can be less expensive and less time-consuming than integrating for On-Premise. The depth of vendor's professional services can also lead to gains in business process re-engineering.

3) If On-Premise maintenance rate increases from $18 \%$ annually to say $20 \%$ or $25 \%$, then Cloud attractiveness will increase.

4) By Year 6, the net advantage of On-Premise runs at roughly $\$ 500 \mathrm{~K}$ per year. So, by 5 years later at Year 10, the cumulative cost advantage for On-Premise is totaling about $\$ 2500 \mathrm{~K}$ less costly.

5) Electing to choose Cloud is a luxury that allows the organization to avoid incurring direct internal costs such as infrastructure headcount, hardware operations, system administration, etc. Recognize that some infrastructure and managerial costs will not be avoided. And tasks for maintaining vendor relations will increase with Cloud versus On-Premise. Gaining access to new Cloud skills and new vendor relationships will be necessary.

6) Enabling the vendor to gain revenue for say training, could reduce pressure by the vendor to increase prices. If the vendor's labor rates or other cost components rose significantly, the vendor's ability to survive could hinge on passing on new pricing [5].

7) As mentioned above, the same vendor may offer both On-Premise and Cloud. If the trend continues that vendors aggressively embrace Cloud, the potential exists that On-Premise will become less and less available, potentially extinct in the future.

\section{At the Edge of the Cloud}

As technology advances, attractive functionality with efficient cost structures can be derived from Cloud or On-Premise implementations. Such architectures and innovation can also generate benefits at the edge. Edge Computing occurs when functionality can benefit from being closer to where distributed systems interact with the physical world.

"The intelligent edge is not a private cloud. It provides a same set of services and operations models as in the public cloud, but it's accessed locally ... similar to operators that manage cable-TV set-top-boxes."

InfoWorld, January 2018 [6] 
Edge Computing can leverage same or similar distributed systems architecture as centralized Clouds. Applications, computations and storage are pushed away from center out to the logical frontier of a network.

The illustration of Cloud computing with Edge components is shown in Figure 5 below.

The promise of Edge computing includes:

- Many of the same efficient cost structures, architecture and compute capabilities that fee-for-service or private clouds possess. Clouds have distributed system architecture and technology in common but characterized by proximity and distance: Centralized Clouds, Edge Clouds and Edge nodes.

- Reduced volumes of data needing transport, shorter distance and less transaction traffic lowers transmittal costs and compresses latency for better service quality.

- De-centralized core computing environment that diminishes bottlenecks, failure or security threats along the data journey.

- Citizen-empowered tools that more flexibly permit options and choices for developers and integrators.

Amazon introduced appliances called Snowball Edge to offer local data processing, easy data movement and stand-alone storage with security and scalability. AWS Snowball Edge is a 100TB data transfer device with on-board storage and compute capabilities for moving large amounts of data into and out of AWS.

"The edge is positioned as a topological design for delivering Internet of Things (IoT), a decentralized alternative to the cloud, or as a high-level topology construct for saving money and reducing latency." Gartner views edge computing as critical for IoT and reimagines application architectures, network design and a complement to hyperscale cloud [7].

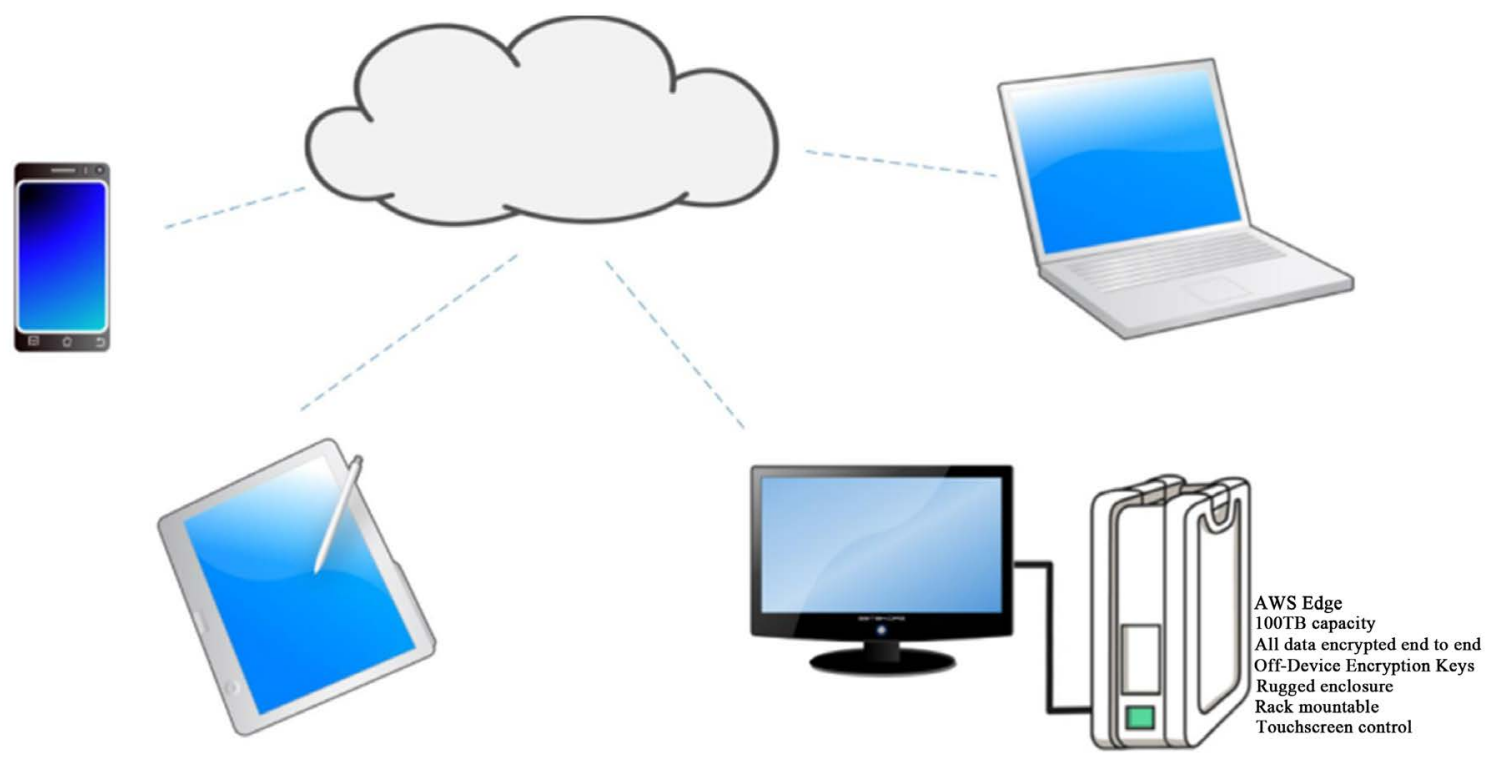

Figure 5. Cloud with edge. 
As components become more distributed, the framework for extending hybrid and multi-cloud environments extend to the edge. Apps can be run anywhere on a variety of platforms. Customers can focus more on their business and less on infrastructure. Ultimately, organizations can better manage, scale and secure from hybrid infrastructure ... to end points that are simpler and less costly to operate.

\section{Conclusions}

This research has pointed out the significance of cost control and governance when deciding on Cloud versus On-Premise computing. Comparisons and calculations were provided to compare the evolving Cloud offerings versus more traditional self-reliant approach. Details of these calculations are highlighted in Figure 6 below. The framework assessed the longer term total cost of ownership with comparisons to the increasingly prevalent subscription model which, for profit-motivated reasons, is the preferred delivery mode of most providers.

If an organization has high confidence in the capacity of internal IT resources and high confidence in their ability to deliver necessary results, then the On-Premise cost structure can be expected to save money over the longer term when compared to Cloud. If, instead, the convenience and flexibility of Cloud is sought, with the extra hand-holding for upgrades and guidance services, and the operating budget can afford an ongoing multi-year Cloud subscription, then relying on the external centralized hosted solution could be more compelling.

Engaging the external Cloud service can free IT resources for other priorities. Essentially, you are outsourcing roles such as Server Hardware Technician and Server Engineer. Other roles that will need adjustment include Storage Administrator,

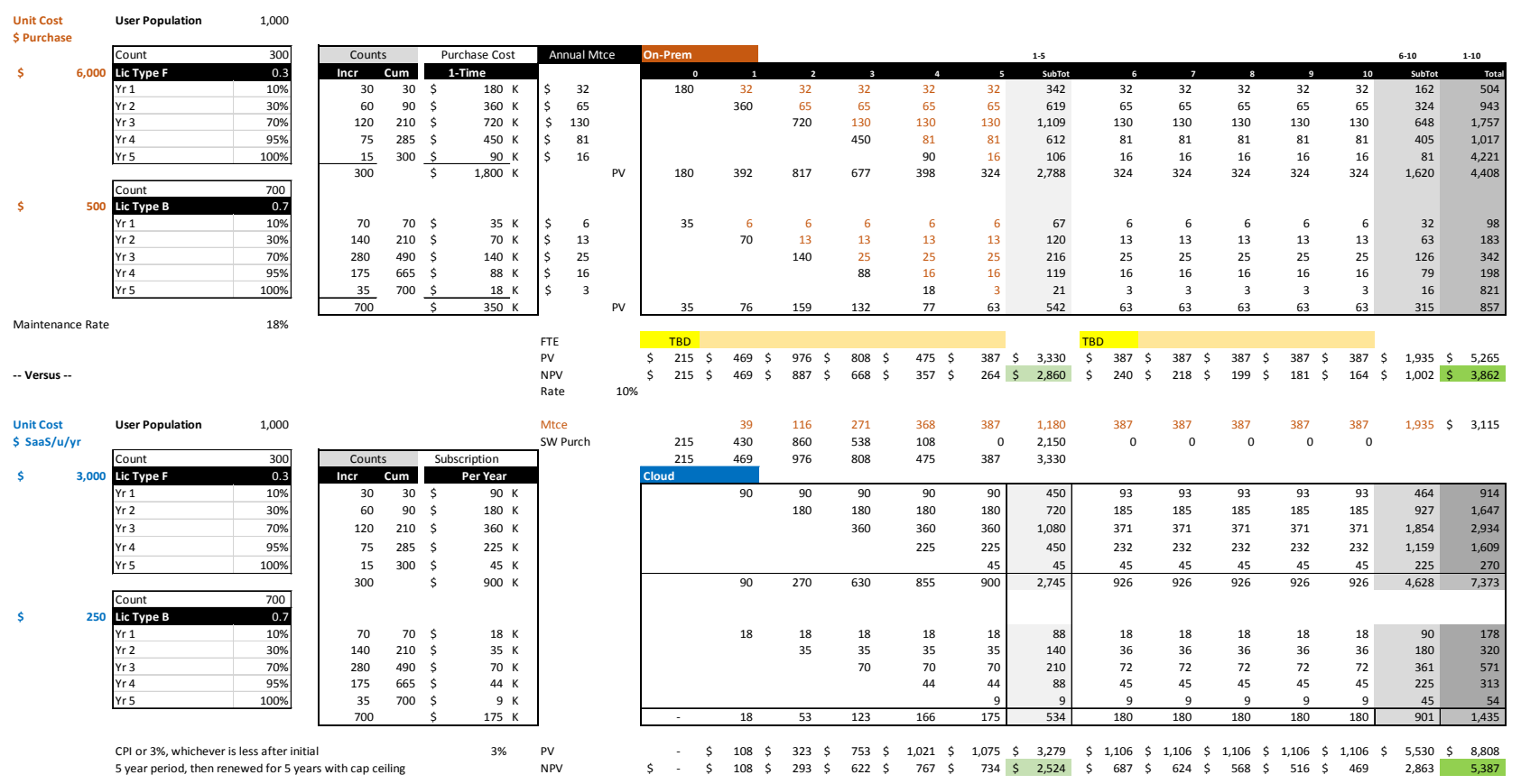

Figure 6. On-Premise versus Cloud-10 year comparison of costs. 
Networking Administrator and Security Specialist. The capital budget would also be less impacted when Cloud subscription (expensed) is chosen over On-Premise license purchases (capitalized).

Gaining visibility and cost control for several interdependent cloud suppliers inside an organization has gained importance. Governing On-Premise, hybrid and public Cloud infrastructures effectively will better balance capital and operational expenses. To accomplish digital transformation, organizations are faced with running the mission while re-inventing it-akin to "changing an airplane's engine during mid-flight."

Going forward, further research and evaluation of Cloud monitoring as a Service is an area that warrants further investigation to gain visibility on cloud-hosted applications. Opportunities for improvements exist in managing uptime, compliance, vulnerabilities, incidents, consolidation, etc. Managing utilization of multi-cloud infrastructure services will be increasingly vital. Especially if On Premise ultimately faces extinction due to supplier's selfish motivations. What best in breed alternatives will emerge for integrating multi-Cloud infrastructure and Edge computing? What precautions make sense to avoid risks when a supplier curtails the architectures and alters product roadmaps?

As mentioned above, the specific cost elements that enable internalizing support for On-Premise can arise from a range of elements. Taking time to understand the contract structure, units of measure, service definitions and T \& C's is critical. Isolating these cost factors is the only way to decomposing TCO and making better decisions about Cloud versus On Premise.

\section{Conflicts of Interest}

The author declares no conflicts of interest regarding the publication of this paper.

\section{References}

[1] Drobik, A. and Maoz, M. (2017) Adapting Your IT Strategy for a Cloud-Dominated Business Application Environment. Gartner.

[2] Choudhary, V. (2017) Software as a Service: Implications for Investment in Software Development. The Paul Merage School of Business, University of California.

[3] Desisto, R. and Paquet, R. (2007) Learn the Economic Advantages of a Pure SaaS Vendor. Gartner.

[4] Gittlen, S. (2017) Cloud vs. On-Premises: Finding the Right Balance. Computerworld.

[5] Lewerke, D. (2017) Adopting Hybrid Cloud Becomes a Strategic Imperative, Harvard Analytic Services, Hybrid Cloud Consulting Practice Insight. Harvard Business Review.

[6] Haviv, Y. (2018) Can Cloud, Big Data and AI Stand More Turmoil? Infoworld.

[7] Gill, R. (2018) How Edge Computing Completes Cloud. Gartner. 


\section{Glossary of Terms}

\begin{tabular}{|c|c|}
\hline Term & Description \\
\hline AWS & Amazon Web Services. \\
\hline Azure & Microsoft Cloud service offering. \\
\hline Cloud Service Provider (Public) & $\begin{array}{l}\text { Amazon Web Services, Microsoft Azure, } \\
\text { Google Cloud Platform. }\end{array}$ \\
\hline Cloud Service Provider (Private) & $\begin{array}{l}\text { HPE, VMware, Dell EMC, IBM, Red Hat, } \\
\text { Microsoft, Open Stack. }\end{array}$ \\
\hline CMaaS & $\begin{array}{l}\text { Cloud monitoring as a Service oversee } \\
\text { interdependent Cloud suppliers. }\end{array}$ \\
\hline COTS & Commercial off the shelf. \\
\hline Container & $\begin{array}{l}\text { Enables software applications to move independently } \\
\text { of computer agnostic of operating system. }\end{array}$ \\
\hline $\mathrm{DR}$ & Disaster recovery. \\
\hline & $\begin{array}{l}\text { Applications, computations and storage are pushed away } \\
\text { from center out to the logical frontier of a network. }\end{array}$ \\
\hline Edge Computing & $\begin{array}{l}\text { Deviceor entry point into enterprise or service provider } \\
\text { core networks. A new complement to application } \\
\text { architectures and network design. See also Snowball below. }\end{array}$ \\
\hline Endpoint & $\begin{array}{l}\text { The user device is an Endpoint. Endpoint } \\
\text { management provides protection, backup, fault tolerance, } \\
\text { restoration and compliance across all user } \\
\text { devices and encrypted data storage. }\end{array}$ \\
\hline HA & High availability. \\
\hline Hybrid Cloud & $\begin{array}{l}\text { A mix of On-Premise, private Cloud and } 3^{\text {rd }} \text { party public } \\
\text { Cloud with orchestration between public and private. }\end{array}$ \\
\hline IaaS & $\begin{array}{l}\text { Infrastructure as a service. Also known as utility } \\
\text { computing or Cloud hosting. }\end{array}$ \\
\hline NAS & Network attached storage. \\
\hline Machine Learning & $\begin{array}{l}\text { Handles large datasets to generate new insights about } \\
\text { customers, products, plants, prices, supply chain, etc. }\end{array}$ \\
\hline $\mathrm{PaaS}$ & Platform as a Service. \\
\hline Partition & $\begin{array}{l}\text { Subset of a computer's resources, virtualized as a } \\
\text { separate computer. VMware is a pioneer and leader } \\
\text { in innovative virtualization and collaboration. }\end{array}$ \\
\hline Red Hat & $\begin{array}{l}\text { Example of a technology company that markets software } \\
\text { for handling Cloud, containers and open software } \\
\text { applications and systems. A range of Cloud providers } \\
\text { use open source for their services and offer tools for } \\
\text { hosting, integrating and managing services. }\end{array}$ \\
\hline SAN & Storage area network. \\
\hline SIAM & Service Integration and Management. \\
\hline Snowball & $\begin{array}{l}\text { Large-scale data transport solution by Amazon to } \\
\text { securely and cost effectively transfer large amounts of } \\
\text { data into and out of the Amazon Web Services Cloud. }\end{array}$ \\
\hline VM & Virtual machine. \\
\hline VPC & Virtual Public Cloud. \\
\hline
\end{tabular}

